\title{
ORIGINAL
}

Grzegorz Koszalka • Jacek Hunicz • Andrzej Rysak •

Grzegorz Litak

\section{Nonlinear vibration of semitrailer suspension: wavelet and multiscale entropy-based approaches}

Received: 30 March 2015 / Accepted: 31 August 2015 / Published online: 11 September 2015

(C) The Author(s) 2015. This article is published with open access at Springerlink.com

\begin{abstract}
We examine the dynamical response of a semitrailer suspension to a real road profile under two different loads. The trailer is a low loader for transporting heavy and large loads, the configuration of which can be adjusted as desired. Experiments are performed on both unladen and 57-ton laden trailers. The acceleration of unsprung and sprung parts of the vehicle is measured. The obtained acceleration time series are then analyzed using the Fourier and wavelet transforms as well as the multiscale entropy approach. The data analysis results reveal transmission of suspension vibration and complexity of vehicle vertical acceleration as a response to the road profile.
\end{abstract}

Keywords Nonlinear vibrations · Wavelets · Multiscale entropy $\cdot$ Vehicle suspension dynamics

\section{Introduction}

The effect of a rough road surface on vehicle vibrations is still researched by automotive manufacturers and research groups [1-7]. These studies usually focus on the drivers' and passengers' comfort during their travel. In the case of goods vehicles, conditions of load carrying are also sometimes taken into account $[8,9]$. For a better understanding of the problem, the behavior of different types of vehicle suspensions was tested under real road conditions. These tests were performed in order to identify and optimize the suspension parameters [10-12], and to minimize tire wear [13]. The relationship between anti-vibration performance and characteristics of a vehicle suspension has been analyzed intensively in recent years [16-18]. Based on real experimental conditions, several models have been proposed. These models take into account such variables as vehicle kinematics, road curvature, and internal vehicle excitations $[12,14,15]$. Despite the visible progresses in simplified vehicle modeling, semitrailer suspensions, especially heavier ones with a modular design, have not been studied extensively. The investigation of such vehicles is particularly important not only because of the structure overload and tire wear but also because of dynamic interaction between the wheels and road surface that causes surface degradation and exerts great impact on road infrastructure such as bridges and railway crossing. What is more, the total mass of heavy semitrailers can vary to a greater extent than it is the case with passenger cars or lorries; a fully laden semitrailer can be four or even more times heavier than an unladen one. The aim of this study was to analyze the vibration of a heavy semitrailer during its operation

G. Koszalka · J. Hunicz · A. Rysak · G. Litak

Faculty of Mechanical Engineering, Lublin University of Technology, Nadystrzycka 36, 20-618 Lublin, Poland

G. Litak $(\bowtie)$

Laboratoire de Génie Electrique et Ferroélectricité, Institut National des Sciences Appliques Lyon, 8 rue de la Physique,

69621 Villeurbanne cedex, France

E-mail: g.litak@pollub.pl

Tel.: +48 815384573

Fax: +48815384233 
under usual road conditions. The results will give additional insight into performance of suspension of heavy modular vehicles. In addition, they can be used to estimate transmitted loads acting on the main supporting structure of a semitrailer. The knowledge of the dynamic overloads is vital to the design process because the assumed overload factor influences the accuracy of strength calculations of a new design [19,20].

The nonlinear dynamics of trailer suspension plays a main role in filtering the rough road excitation in a wide range of loading and in the presence of the coupling force from the tractor. Our study compares road excitations of the driving unsprung elements and the sprung platform in certain (natural) conditions concerning the two extreme cases: semitrailers unloaded and fully loaded. Both cases are important for producers and users of semitrailers due to transport safety, costs of operation, and maintenance of cargo transported in good condition. In the case of empty trailer (light transport), suspension system is more stiff, resulting in increased transmission of vibration into the platform. With a maximum load of energy, transmission can be caused by a failure of the suspension system with specific excitations that might occur under working conditions. The proposed studies would allow to evaluate the efficiency of the suspension system in both extreme cases, when operating in seminatural conditions.

\section{Object and conditions of measurements}

The examinations were conducted on a prototype of a modular semitrailer for carrying oversized and heavy loads up to 60 tons. Depending on the requirements, the length of the semitrailer platform can be extended, and the number of axles can be set to 2,3 , or 5 . The number of axles can be changed owing to the modular structure of the trailer. The semitrailer can be used as a 2- or 3-axle bogie vehicle, or both. All of the axles are equipped with steered twin wheels and tires $245 / 70 R$ 17.5. The nominal load of the axles is 12 tons. The maximum construction weight of the semitrailer is 84 tons. The semitrailer is equipped with a typical air suspension consisting of a control arm, an air bag, and a hydraulic shock absorber. A schematic design of the semitrailer used in the experiments is shown in Fig. 1.

The vibration data were measured using PCB Piezotronic manufactured equipment. Single-axis accelerometers type ICP M338A34 with an average sensitivity of $1 \mathrm{mV} /\left(\mathrm{m} / \mathrm{s}^{2}\right)$ were used. Their measurement range was $+/-4900 \mathrm{~m} / \mathrm{s}^{2}$, and their frequency range was from 0.7 to $3000 \mathrm{~Hz}$. The acceleration signals were conditioned with the use of a four-channel amplifier type 482A16. A DAQPad 6070E from National Instruments was used for data acquisition. The maximum sampling frequency was set to $1.25 \mathrm{MHz}$, and resolution of analog-todigital converter was 12 bits. In order to utilize the whole scale of the converter, the voltage amplification of the signals was set to 100 , and the measurement range was varied according to maximum signal amplitude. During the research, four vibration transducers mounted on the front axle of the trailer suspension were used. Two transducers were mounted at the flat spring rocker arms close to the right and left wheel axes, and the other two were mounted on the body above the right and left rocker arms mounting pins. Such configuration of the measurement points enabled measurement of both sprung (body) and unsprung (wheel axles) acceleration (Fig. 2).

The measurements were taken on a 5-axle semitrailer in two cases: (a) unladen semitrailer; (b) semitrailer loaded with 57 tons. During the experiments, the semitrailer was hauled by a 3-axle semitrailer truck at a speed of $9 \mathrm{~km} / \mathrm{h}$ through the same section of the ground paved with concrete blocks. The vibration data were recorded simultaneously by four measurement transducers with sampling rate of $20 \mathrm{kHz}$ per channel. At each measurement event, up to 200,000 samples were recorded.

\section{Experimental results}

The collected data for the unladen semitrailer are given in Fig. 3a-d and for the laden one in Fig. 4a-d. Note that the unsprung mass vibrations generally have a higher amplitude and, additionally, are characterized by

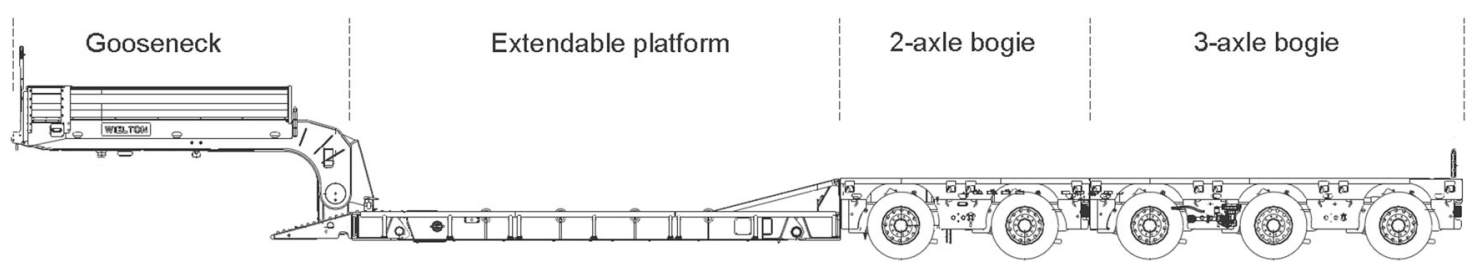

Fig. 1 Sketch of the semitrailer used for investigation 


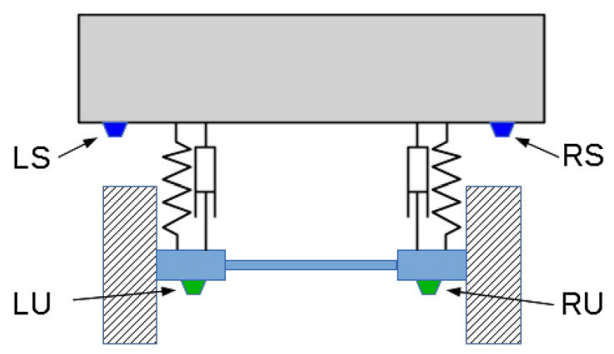

Fig. 2 Schematic illustration of the mounting points for sensors. Sprung and unsprung mass sensors are marked in blue and green colors, respectively (see the notation abbreviations in Table 1). (Color figure online)

Table 1 Sensor abbreviation notation

\begin{tabular}{lll}
\hline Sensor & Left side & Right side \\
\hline Sprung & LS & RS \\
Unsprung & LU & RU \\
\hline
\end{tabular}

(a)

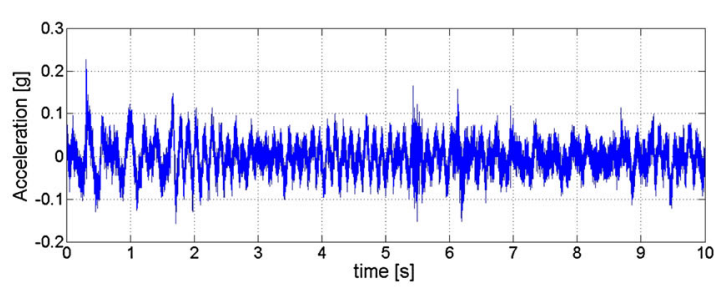

(c)

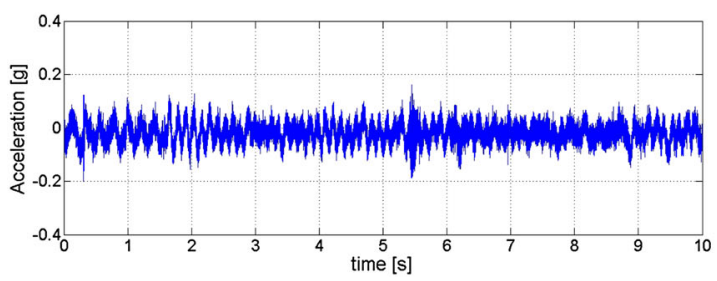

(b)

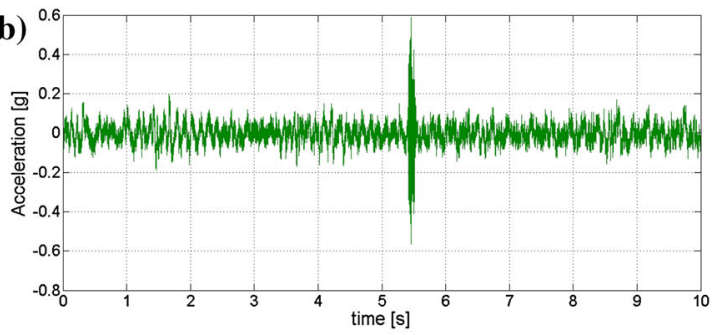

(d)

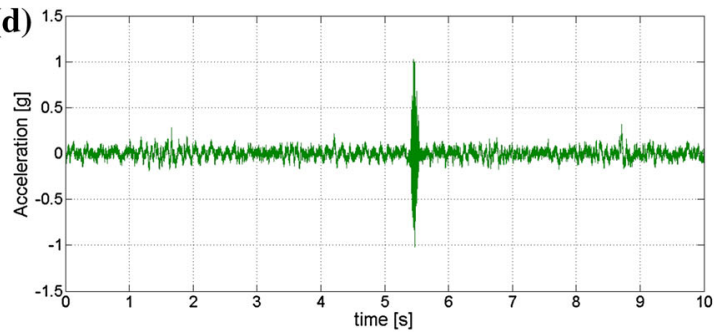

Fig. 3 Results of the acceleration measurements for the unladen semitrailer as collected by LS, LU, RS, RU sensors (a-d, respectively)

sudden increases in their value. This was caused by the external event surface irregularity. The results of vibration measurements of the semitrailer moving at a speed of $9 \mathrm{~km} / \mathrm{h}$ on the surface made of cobblestones were analyzed.

This interesting events could be investigated in a frequency domain. Consequently, the Fourier transform can be employed to provide the system response features including frequency of transmission of vibration through the suspension system. The results of the FFT were limited to $0-60 \mathrm{~Hz}$ band. The results for the unladen semitrailer are presented in Fig. 5a, b and for the laden one in Fig. 5c, d. Interestingly, we observed two peaks (for the frequency $f$ of about 3 and $8 \mathrm{~Hz}$ ) in the left- and right-hand side sensors of the unladen semitrailer. In laden trailer case, the peaks observed in the frequency spectrum of sprung masses decrease to about 1.5 and $4 \mathrm{~Hz}$ as an effect of a fairly larger load participating in sprung masses. The resulting signal transmittance $\operatorname{Tr}(f)$ can be expressed as:

$$
\operatorname{Tr}(f)=\frac{\text { Acc }_{\mathrm{s}}}{\mathrm{Acc}_{\mathrm{u}}},
$$

where $\operatorname{Acc}_{\mathrm{u}}(f)$ and $\operatorname{Acc}_{\mathrm{s}}(f)$ are the unsprung and sprung accelerations, respectively. Note that in the most of the frequency region, the vibrations are damped effectively, and the resulting transmittance is less than unity. The damping of vibration is less effective in the range of $2-7 \mathrm{~Hz}$ and, especially in the case of unladen trailer, in the ranges of $40-45$ and $55-58 \mathrm{~Hz}$. 

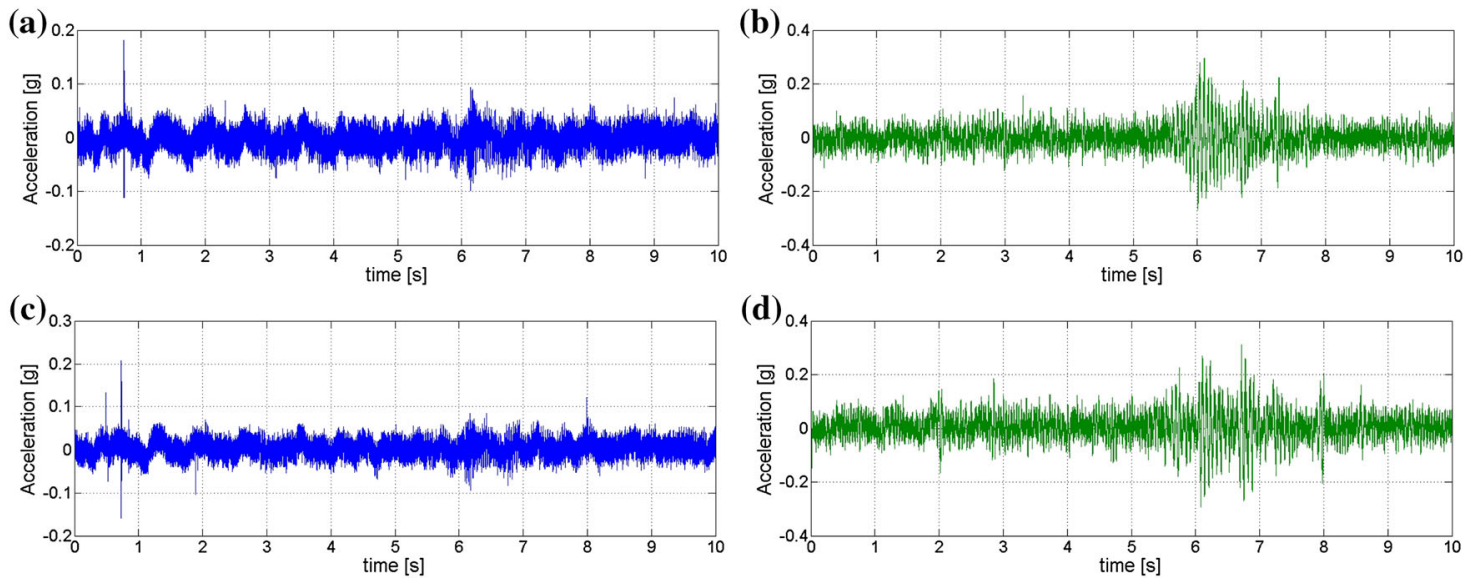

Fig. 4 Results of the acceleration measurements for the laden semitrailer as collected by LS, LU, RS, RU sensors (a-d, respectively)
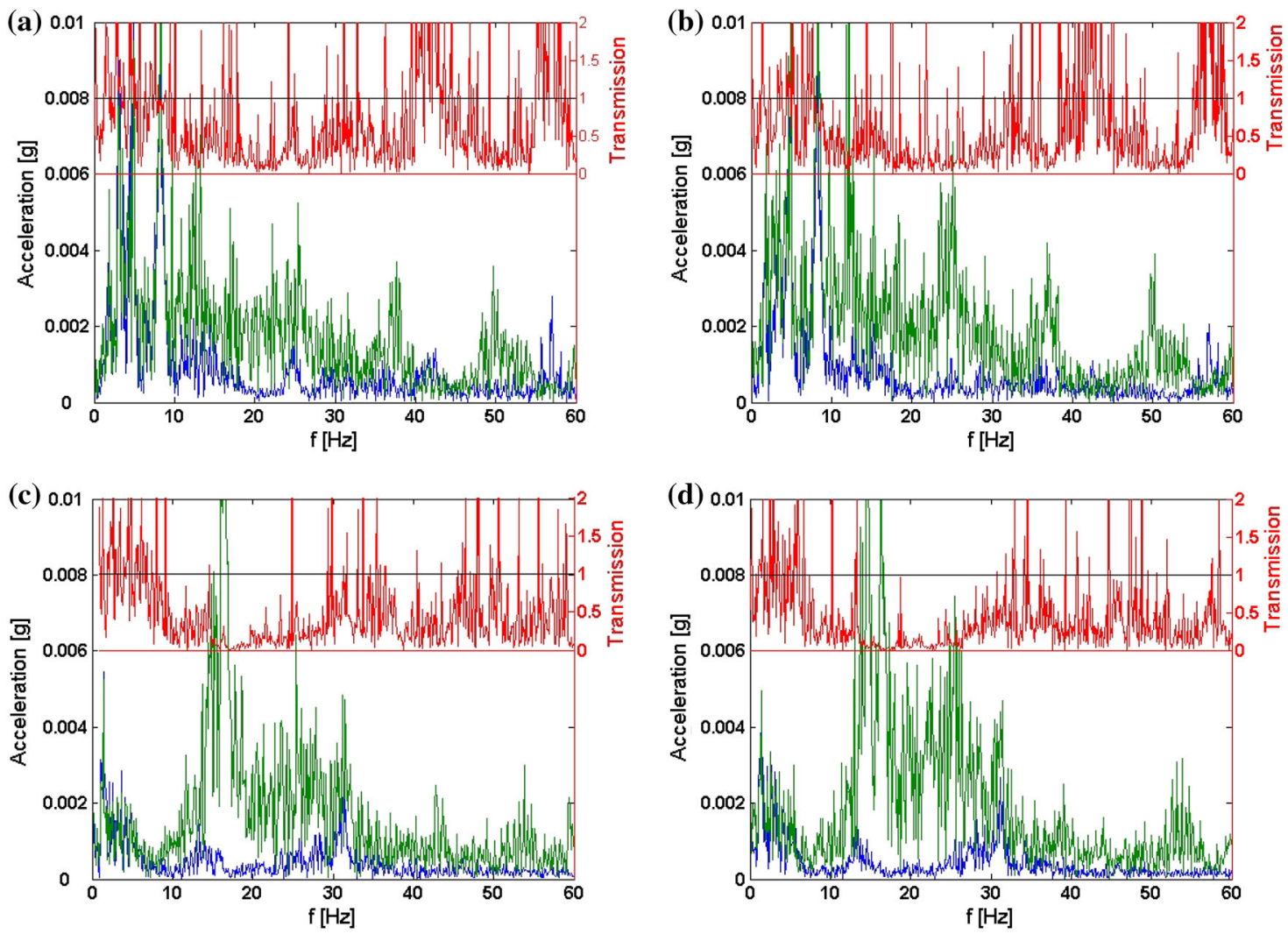

Fig. 5 Results obtained on the basis of FFT for driving with unladen trailer $(\mathbf{a}, \mathbf{b})$ and laden $(\mathbf{c}, \mathbf{d})$. Blue line indicates sprung masses $\operatorname{Acc}_{\mathrm{s}}(f)$, the green indicates unsprung masses $\operatorname{Acc}_{\mathrm{u}}(f)$, and the red line denotes the calculated transmittance $\operatorname{Tr}(f)(\operatorname{see}$ Eq. 1). (Color figure online)

\section{Wavelet analysis}

For better clarity, we have also performed the wavelet analysis. Namely, we studied the time series $\operatorname{Acc}_{\mathrm{i}}(t)$ $(i=s$ or $u$ ) given by the continuous wavelet transform (CWT) [21,22]. The corresponding continuous wavelet transform with respect to a wavelet function $\psi($.$) is defined as follows:$ 

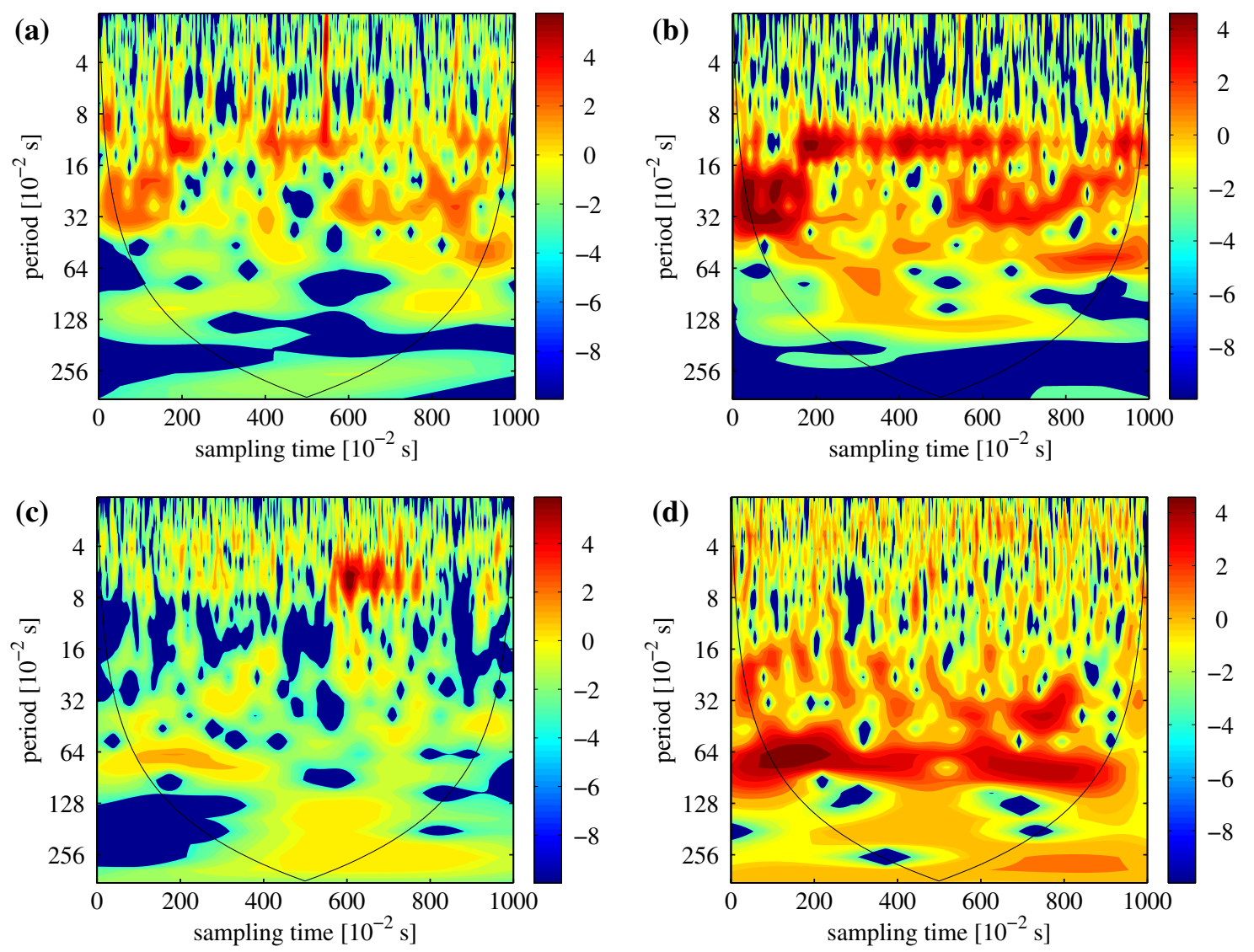

Fig. 6 Wavelet results of the acceleration measurements for the laden semitrailer as collected by LS, LU, RS, RU sensors (a-d, respectively)

$$
W_{\mathrm{s}, \mathrm{n}}\left(\operatorname{Acc}_{\mathrm{u} / \mathrm{s}}\right)=\sum_{i=1}^{N} \frac{1}{s} \psi\left(\frac{i-n}{s}\right) \frac{\left(\operatorname{Acc}_{\mathrm{u} / \mathrm{s}}\left(t_{i}\right)-<\operatorname{Acc}_{\mathrm{u} / \mathrm{s}}>\right)}{\sigma_{\mathrm{Acc}(\mathrm{u} / \mathrm{s})}}
$$

where $<\mathrm{Acc}_{\mathrm{u} / \mathrm{s}}>$ and $\sigma_{\mathrm{Acc}(\mathrm{u} / \mathrm{s})}$ are the averages and standard deviations for unsprung and sprung accelerations, respectively, and $t_{i}$ is the sampling time. Finally, the wavelet $\psi(t)$ is referred to as the mother wavelet, and the letters $s$ and $n$ denote the scale and the time index, respectively. The wavelet power spectrum (WPS) of the $\mathrm{Acc}_{\mathrm{u} / \mathrm{s}}$ time series is defined as the square modulus of the CWT:

$$
P_{\mathrm{W}}=\left|W_{\mathrm{s}, \mathrm{n}}\right|^{2} \text {. }
$$

In our calculations, we have used a complex Morlet wavelet as the mother wavelet. The Morlet wavelet consists of a plane wave modulated by a Gaussian function and is described by

$$
\psi(\eta)=\pi^{-1 / 4} \mathrm{e}^{i \theta_{0} \eta} \mathrm{e}^{-\eta^{2} / 2},
$$

where $\theta_{0}$ is the center frequency, also referred to as the order of the wavelet, $\eta$ is a renormalized time variable.

The value of $\theta_{0}$ defines the number of oscillations in the wavelet and thus controls the time-frequency resolutions. In our analysis, we used $\theta_{0}=6$ This choice provides a good balance between the time and frequency resolutions. Also, for this choice, the scale is approximately equal to the period, and therefore, the terms scale and period can be interchanged for interpreting the results. For general discussion, see [21-23].

The corresponding results of CWT as the wavelet power spectra are presented in Fig. 6. One can see two characteristic periods 0.12 and $0.32 \mathrm{~s}$ of the unladen vehicle; 0.32 and $0.64 \mathrm{~s}$ of the laden vehicle. This is consistent with the corresponding frequency peaks in Fig. 5. Moreover, by using CWT, one can see the evolution of the response amplitude and frequency in time domain. The colors also help us to distinguish time-localized events (Fig. 6c) as well as the intermittent behavior mainly for the unsprung masses. Generally, the spectra in Fig. 6a, c are more uniform due to random wheel excitation by road surface corrugation. 


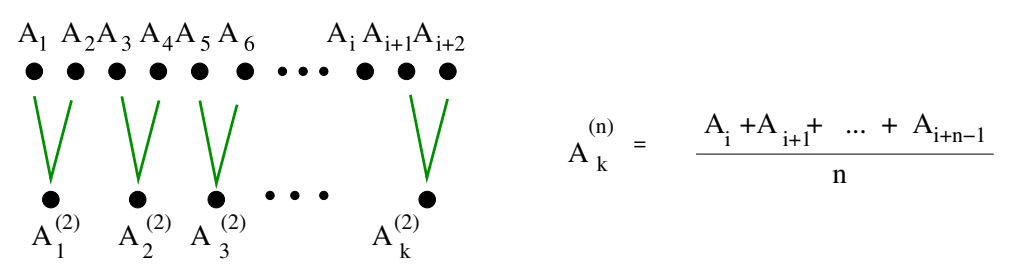

Fig. 7 Schema of multiscale entropy calculation. $A_{i}$ denotes sampled accelerations

\section{Composite multiscale entropy approach}

To gain more insight into complex systems and their nonlinear behavior, the multiscale entropy $[24,25]$ analysis is widely used $[7,26,27]$. This method provides, for measured signals, a relative level of complexity of finite length time series. Unfortunately, there is no consensus over the complexity definition, but it is combined with "meaningful structural richness" [28] contained over multiple spatial and temporal correlations.

The concept of multiscale entropy (MSE) $[24,25]$ is based on the coarse-graining procedure that uses a coarse-grained time series, as an average of the original data points within nonoverlapping windows by increasing the scale factor $\tau$ according to the following formula (see Fig. 7):

$$
A_{j}^{(\tau)}=\frac{1}{\tau} \sum_{i=(j-1) \tau+1}^{j \tau} A_{i},
$$

where $A_{i}$ is a raw one-dimensional acceleration time series $x=\left\{A_{1}, A_{2}, \ldots, A_{N}\right\}$. In this approach for each scale factor $\tau$, the MSE calculation based on the time series of the coarse-grained $A_{j}^{(\tau)}$ :

$$
\operatorname{MSE}(x, \tau, m, r)=\operatorname{SampEn}\left(A^{(\tau)}, m, r\right) .
$$

where $m=2$ is the pattern length, and $r$ is the similarity criterion which is usually set to be $r<\sigma$ [24]; here, $\sigma$ is the standard deviation of the original time series and $A_{i}^{(1)}=A_{i}$.

To estimate SampEn $\left(A^{(\tau)}, m, r\right)$ from Eq. 6 (see also Fig. 7), we count the number of vector pairs denoted by $A^{(\tau)}(i)$ and $A^{(\tau)}(j)$ in the time series of length $m$ and $m+1$ having the distance $d\left[A^{(\tau)}(i), A^{(\tau)}(j)\right]<r$. We denote them by $P_{m}$ and $P_{m+1}$, respectively. Finally, we define the sample entropy to be [29]:

$$
\operatorname{SampEn}\left(A^{(\tau)}, m, r\right)=-\log \frac{P_{m+1}}{P_{m}} .
$$

Strictly speaking, it is a shortcoming of the logarithm of the conditional probability that two sequences with a tolerance $r$ form points that remain within $r$ of each other at the next point.

Continuing these research efforts, Wu et al. [26] introduced the concept of a composite multiscale entropy (CMSE), which for higher scale factor provides entropy more reliably than the usual multiscale entropy by including multiple combinations of neighbor points. The prescribed algorithm for CMSE calculations is the following formula:

$$
\operatorname{CMSE}(x, \tau, m, r)=\frac{1}{\tau} \sum_{k=1}^{\tau} \operatorname{SampEn}\left(a_{k}^{(\tau)}, m, r\right) .
$$

In the present paper, the CMSE is applied for real signals reporting a different behavior of the system characterized by the time series in Figs. 3 and 4. The voltage output results of composite multiscale entropy calculation are usually provided for several similarities $r$ for different CMSE values with increasing the scale factor $\tau$. The appearance of higher values of CMSE corresponds to the presence of higher complexity within the analyzed signal. It can be noticed that there is a variation in the irregularity of the system as a different $\tau$ is chosen.

The CMSE results, for the chain length of $m=2$ and similarity criterion $r=0.2 \sigma$, are presented in Fig. 8 . The CMSE for laden semitrailer at the unsprung point (green line) is higher than for the sprung point (blue line) as shown in Fig. 8a, b. This can be explained by the fact that the unsprung vehicle part undergoes significant in the vibration signal, which correspond to the signal carrying some information about the ground noise. 

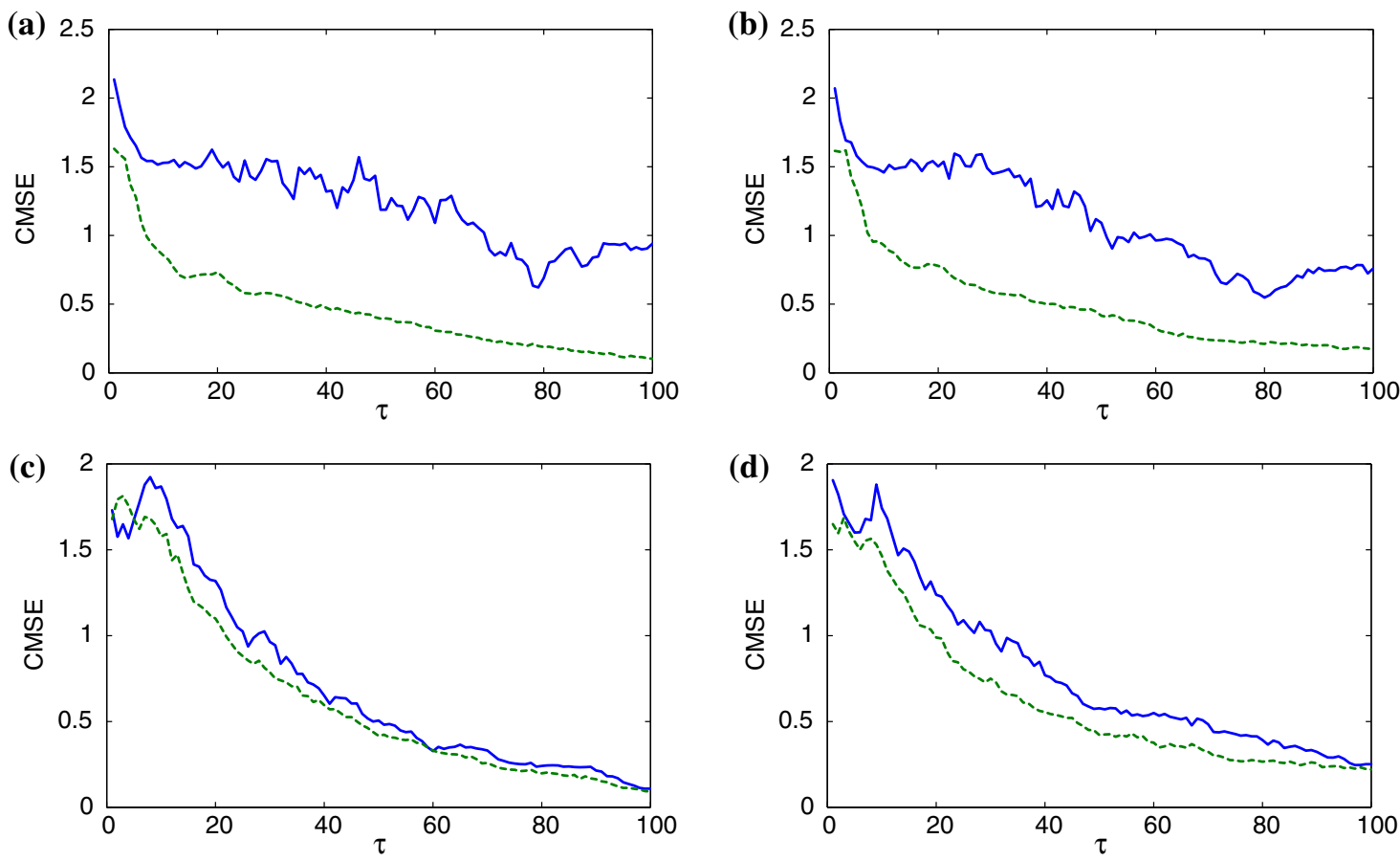

Fig. 8 Multiscale entropy calculated for the acceleration measurements for the laden $(\mathbf{a}, \mathbf{b})$ and unladen $(\mathbf{c}, \mathbf{d})$ semitrailers. The acceleration signal was collected from the left $(\mathbf{a}, \mathbf{c})$ and right $(\mathbf{b}, \mathbf{d})$ sides. The green (with dashed line) and blue (with full line) colors correspond to the unsprung and sprung measurement points of the semitrailer. The sampling for entropy calculations was reduced by 100 times with respect to the measured data presented in Figs. 3 and 4

Therefore, the entropy has a relatively low value. At the sprung part, these changes are selectively suppressed and complexity increases. Interestingly, the sprung response is close to the pink noise (more flat curves), while the unsprung response indicates rather the white noise (a hyperbola-like curves).

On the other hand, with the unladen semitrailer, the difference between the unsprung and sprung response entropy is fairly small as a result of larger vibration transmission (Fig. 8c, d). Both of responses (sprung and unsprung) indicate the white noise type of excitation (a hyperbolic shape of curves). Simply, the semitrailer suspension is designed to damp more effectively vibrations in the laden case.

\section{Conclusions}

We have analyzed the effect of load on vibration transmission through the heavy semitrailer suspension. The suspension operates satisfactorily, showing in a wide region of frequencies a fairly low value of vibration transmission $\operatorname{Tr}(f)<1$. However, acceleration amplitudes of unsprung and sprung masses in a low-frequency range (up to $7 \mathrm{~Hz}$ ) both for the laden and unladen vehicle are similar, which suggests that the suspension does not provide proper damping. In the range of higher frequencies, damping effectiveness increases both for the unladen and laden vehicles. Comparing the absolute values of the amplitudes for laden and unladen semitrailers, we found that they are higher for a relatively light vehicle. Additionally, the higher load provided more effective damping. We also observed a reflection of the resonance peaks of the sprung mass in the Fourier and Wavelet spectra where the transmission increased considerably. In particular, the wavelets enabled to investigate the transient and nonstationary behavior and the corresponding sprung mass responses including the time localizations of vibrations and intermittent behavior. On the other hand, the multiscaled entropy revealed a huge difference with respect to the sprung and unsprung parts in the laden vehicle case. At the same time, however, this difference does not hold for the unladen semitrailer case, which confirms that the semitrailer suspension works efficiently in the laden trailer case. To provide more information about the suspension system, it is necessary to perform a series of new tests that will take into account different road profiles and surfaces as well as various loading and vehicle speeds. 
Acknowledgments This research was funded by the Polish National Centre for Research and Development under Grant No. 6 ZR6 2009 C/07232.

Open Access This article is distributed under the terms of the Creative Commons Attribution 4.0 International License (http:// creativecommons.org/licenses/by/4.0/), which permits unrestricted use, distribution, and reproduction in any medium, provided you give appropriate credit to the original author(s) and the source, provide a link to the Creative Commons license, and indicate if changes were made.

\section{References}

1. Andrzejewski, R., Awrejcewicz, J.: Nonlinear Dynamics of a Wheeled Vehicle. Springer, New York (2005)

2. Verros, G., Natsiavias, S., Stepan, G.: Control and dynamics of quarter car models with dual-rate damping. J. Vib. Control 6, 1045-1063 (2000)

3. Ibrahim, I.M., Crolla, D.A., Barton, D.C.: The impact of the dynamic tractor-semitrailer interaction on the ride behaviour of fully-laden and unladen trucks. SAE Technical Paper 2004-01-2625 (2004)

4. Von Wagner, U.: On nonlinear stochastic dynamics of quarter car models. Int. J. Non-Linear Mech. 39, 753-765 (2004)

5. Turkay, S., Akcay, H.: A study of random vibration characteristics of the quartercar model. J. Sound Vib. 282, 111-124 (2005)

6. Litak, G., Borowiec, M., Hunicz, J., Koszalka, G., Niewczas, A.: Vertical vibrations of a delivery car excited by railway track crossing. Chaos Solitons Fractals 42, 270-276 (2009)

7. Borowiec, M., Sen, A.K., Litak, G., Hunicz, J., Koszalka, G., Niewczas, A.: Vibrations of a vehicle excited by real road profiles. Forschung im Ingenieurwesen 74, 99-109 (2010)

8. Lu, F., Ishikawa, Y., Kitazawa, H., Satake, T.: Effect of vehicle speed on shock and vibration levels in truck transport. Packag. Technol. Sci. 23, 101-109 (2010)

9. Gebresenbet, G., Aradom, S., Bulitta, F.S., Hjerpe, E.: Vibration levels and frequencies on vehicle and animals during transport. Biosyst. Eng. 110, 10-19 (2011)

10. Cao, D., Rakheja, S., Su, C.-Y.: Heavy vehicle pitch dynamics and suspension tuning. Part I: Unconnected Suspens. Veh. Syst. Dyn. 46, 931-953 (2008)

11. Huizinga, A.T.M.J.M., Van Ostaijen, M.A.A., Van Oosten Slingeland, G.L.: A practical approach to virtual testing in automotive engineering. J. Eng. Des. 13, 33-47 (2002)

12. Lee, J., Thompson, D.J., Yoo, H.H., Lee, J.M.: Vibration analysis of a vehicle body and suspension system using a substructure synthesis method. Int. J. Veh. Des. 24, 360-371 (2000)

13. Braghin, F., Cheli, F., Melzi, S., Resta, F.: Tyre wear model: validation and sensitivity analysis. Meccanica 41, 143-156 (2006)

14. Verros, G., Natsiavas, S., Papadimitriou, C.: Design optimization of quarter-car models with passive and semi-active suspensions under random road excitation. J. Vib. Control 11, 581-606 (2005)

15. Xuebao, Z.G.: Experimental and calculation methods for determining damping properties of the inertia track in a hydraulic engine mount. J. Vib. Eng. 19, 376-381 (2006)

16. Zhang, Y., Ren, C.: Test analysis on relationship between anti-vibration performance and chaos characteristics of vehicle suspension. J. Southeast Univ. 22, 64-68 (2006)

17. Ksiazek, M.A., Luczko, J.: Optimal vibration isolation of a tractor-semi-trailer system. Veh. Syst. Dyn. 45, 277-289 (2007)

18. Yarmohamadi, H., Berbyuk, V.: Kinematic and dynamic analysis of a heavy truck with individual front suspension. Veh. Syst. Dyn. 51, 877-905 (2013)

19. Kurdi, O., Rahman, R.A.: Finite element analysis of road roughness effect on stress distribution of heavy duty truck chassis. Int. J. Technol. 1, 57-64 (2010)

20. Debski, H., Koszalka, G., Ferdynus, M.: Application of FEM in the analysis of the structure of a trailer supporting frame with variable operation parameters. Eksploatacja i Niezawodnosc-Maintenance and Reliability. 14, 107-114 (2012)

21. Kumar, P., Foufoula-Georgiou, E.: Wavelet analysis for geophysical applications. Rev. Geophys. 35, 385-412 (1997)

22. Torrence, C., Compo, G.P.: A practical guide to wavelet analysis. Bull. Amer. Meteor. Soc. 79, 61-78 (1998)

23. Geca, M., Wendeker, M., Litak, G.: Combustion variability and uniqueness in cylinders of a large power radial engine. J. Vibroeng. 14, 582-590 (2012)

24. Costa, M., Peng, C.-K., Goldberger, A.L., Hausdorff, J.M.: Multiscale entropy analysis of human gait dynamics. Phys. A 330, 53-60 (2003)

25. Costa, M., Goldberger, A.L., Peng, C.-K.: Multiscale entropy analysis of biological signals. Phys. Rev. E 71, 021906 (2015)

26. Wu, S.-D., Wu, C.-W., Lin, S.-G., Wang, C.-C., Lee, K.-Y.: Time series analysis using composite multiscale entropy. Entropy 15, 1069-1084 (2013)

27. Borowiec, M., Rysak, A., Betts, D.H., Bowen, C.R., Kim, H.A., Litak, G.: Complex response of the bistable laminated plate: multiscale entropy analysis. Eur. Phys. J. Plus 129, 211 (2014)

28. Grassberger, P.: Information and complexity measures in dynamical systems. In: Atmanspacher, H., Scheingraber, H. (eds.) Information Dynamics, pp. 15-33. Plenum Press, New York (1991)

29. Richman, J.S., Moorman, J.R.: Physiological time-series analysis using approximate entropy and sample entropy. Am. J. Physiol. Heart Circ. Physiol. 278, H2039-H2049 (2000) 